\title{
EFFECT OF INGESTING TRAINING TOWARDS DYSPHAGIA IN STROKE' PATIENTS IN HAJI HOSPITAL AND MAKASSAR CITY HOSPITAL
}

\author{
Afrida $^{1}$ \\ ${ }^{1}$ Dosen, STIKES Nani Hasanuddin Makassar \\ e-mail: Randayaumul95@gmail.com
}

\begin{abstract}
Introduction: Stroke is a loss of brain function caused by the cessation of blood supply to the brain. One of the most common clinical disorders of stroke is ingesting or dysphagia. This study aims to identify the effect of ingesting exercise to stroke patients with dysphagia in the General Hospital of Haji General Hospital of Makassar City. Method: The design of this study was pre experimental with One Group Pre-Post Test Design. Samples in this study were all stroke patients with dysphagia with Convenience Sampling technique, obtained 20 respondents. Rehabilitation of ingesting exercise is done three times a day at breakfast, lunch, and dinner for seven days in a row. Evaluation of respondents' ingesting status was done on the first day before exercise and last day after practicing exercise. Result: Bivariate results showed that there was an influence between stroke patients with dysphagia and ingesting exercises $(\mathrm{p}<0.001)$. Conclusion: It is further recommended that nurses perform structured ingesting exercises as self-care nursing intervention in dealing with stroke patients who have dysphagia.
\end{abstract}

Keywords: stroke, dysphafagia, ingesting exercise

\section{PENDAHULUAN}

World Health Organization (WHO) mendefinisikan bahwa stroke merupakan tanda-tanda klinis yang berkembang cepat akibat gangguan fungsi otak fokal atau global yang dapat mengakibatkan kematian atau kelainan yang menetap lebih dari 24 jam, tanpa penyebab lain kecuali gangguan vaskular (Rasyid \& Soertidewi, 2011).

Di Amerika Serikat, kejadian baru stroke diperkirakan sekitar 400.000 orang pertahun. Data statistik menunjukkan hampir empat juta orang di Amerika Serikat menderita stroke dan mereka hidup dengan mengalami sisa akibat stroke (Rasyid \& Soertidewi, 2011)

Berdasarkan hasil Riskesdas (2013), Prevalensi stroke berdasarkan diagnosis nakes tertinggai di Sulawesi Utara (10,8\%) dan Yogyakarta (10,3\%). Sedangkan prevalensi kasus stroke berdasarkan yang terdiagnosis nakes dan gejala tertinggi terdapat di provensi Sulawesi Selatan $(17,9 \%)$ dan terendah Provinsi Riau yang terendah $(5,2 \%)$.

Makassar sebagai kota di provinsi Sulawesi Selatan yang tingkat prevalensi penyakit tidak menular (PTM) telah melampaui rata-rata prevalensi nasional seperti hipertesi, diabetes militus, jantung koroner, stroke dan kanker. Berdasarkan data Kemenkes diketahui, prevalensi penyakit hipertensi $28,8 \%$, diabetes militus 5,3\%, jantung koroner sebesar $4,2 \%$, gagal jantung $0,8 \%$, kanker $0,22 \%$, dan stroke $2,9 \%$ (Kemenkes, 2016).

Masalah kesehatan yang timbul akibat stroke sangat bervariasi, tergantung pada luasnya daerah otak yang mengalami nekrosis atau kematian jaringan, dan lokasi yang terkena. Salah satu gangguan klinis yang sering ditemukan akibat stroke adalah gangguan menelan atau disfagia 
(Rasyid \& Soertidewi, 2011)

Disfagia adalah kesulitan menelan cairan atau makanan yang disebabkan gangguan pada proses menelan (Rasyid \& Soertidewi, 2011). Ditemukan sekitar 28-65\% pasien yang mengalami disfagia setelah serangan stroke. Setelah dilakukan rehabilitasi selama 14 hari pasca stroke, sekitar 90\% pasien dapat melakukan latihan menelan (Smithard, 2014).

Berdasarkan hasil penelitian oleh Mc Cullough \& Kim (2013), didapatkan 18 pasien stroke dengan disfagia dilakukan latihan menelan dengan tekhnik mandelshon manuver. Semua pasien mengalami peningkatan status menelan setelah di lakukan latihan menelan selama 1-2 minggu.

Pasien stroke dengan disfagia dapat mengkibatkan terjadinya malnutrisi, dehidrasi, infeksi saluran nafas, lamanya jumlah hari rawat, dan bahkan kematian (Jenny, J, 2014). Untuk mencegah terjadinya hal tersebut, diperlukan deteksi dini adanya disfagia pada semua pasien stroke sejak pasien masuk rumah sakit. Selain untuk mencegah terjadinya aspirasi, juga untuk menetapkan penatalaksanaan pemasukan nutrisi yang tepat dan akurat bagi pasien (Rasyid \& Soertidewi, 2011).

Perawat sebagai bagian dari tim kesehatan, bertanggung jawab untuk menangainya secara profesional sesuai standar yang telah ditetapkan salah satunya adalah dengan latihan menelan (Rasyid \& Soertidewi, 2011).

Hasil catatan Medik di Rumah Sakit Umum Daerah (RSUD) Haji Kota Makassar, jumlah pasien rawat inap dengan kasus stroke pada JanuariSeptember 2016 sebanyak 42 pasien dengan rata-rata 5 pasien perbulan. Dan berdasarkan catatan Medik RSUD Kota Makassar, jumlah pasien stroke pada Januari-Oktober 2016 sebanyak 135 pasien dengan rata-rata 13 pasien perbulan (Rekam Medis RSUD Haji Makassar dan RSUD Kota Makassar, 2016).

Berdasarkan hasil observasi dan wawancara dengan perawat di RSUD Haji Makassar dan RSUD Kota Makassar didapatkan belum adanya, penanganan secara khusus dan komprehensif pasien stroke yang mengalami disfagia. hal ini didukung dengan pengkajian disfagia belum dilakukan secara intensif, belum dilakukan latihan mengunyah dan menelan secara terstruktur sehingga perkembangan kemampuan menelan belum terukur dengan baik. Perawat juga belum memanfaatkan keterlibatan pasien dan keluarga secara optimal dalam mempersiapkan perawatan mandiri baik saat di rumah sakit maupun setelah pulang dari rumah sakit. Sehingga risiko kematian menjadi lebih besar pada pasien stroke yang disertai disfagia bila tidak ditangani secara tepat, serta lama hari perawatan menjadi lebih panjang dan biaya yang ditanggung pasien menjadi lebih mahal. Penanganan disfagia dengan latihan menelan ditujukan untuk menurunkan risiko aspirasi, meningkatkan kemampuan makan dan menelan serta mengoptimalkan status nutrisi.

\section{METODE}

Lokasi, populasi dan sampel

Penelitian ini dilakukan pada tanggal 15 Desember - 15 desember 2017 di RSUD Haji Makassar dan RSUD Kota Makassar. Penelitian ini merupakan eksperimental dengan jenis rancangan one group pre-post test design yaitu eksperimen dengan cara sampel diobservasi sebelum dilakukan intervensi, kemudian diobservasi lagi setelah dilakukan intervensi. Populasi adalah semua pasien stroke yang dirawat di RSUD Haji Makassar dan RSUD Kota Makassardan RSUD Makassar. Dan sampel pada penelitian ini adalah 20 rsponden stroke dengan disfagia yang memenuhi kriteria inklusi. Teknik sampling yaitu teknik convinience sampling.

Pengumpulan Data

1. Editing merupakan kegiatan untuk pengecekan dan perbaikan isian 
formulir atau kusioner

2. Coding yakni mengubah data berbentuk kalimat atau huruf menjadi data angka atau bilangan.

3. Tabulation yakni data tersebut dimasukkan kedalam table tertentu sifat-sifat yang dimiliki sesuai dengan tujuan penelitian.

\section{Analisa Data}

a. Analisis Univariat

Dilakukan terhadap tiap variable penelitian dan umumnya hanya menghasilkan distribusi dan persentase dari setiap variable.

b. Analisis Bivariat

Dilakukan terhadap dua variable yang diduga ada hubungan atau korelasi

\section{HASIL PENELITIAN}

1. Analisis Univariat

\begin{tabular}{clcc}
\hline & & Frekuensi & Persentase(\%) \\
\hline Umur & $25-40$ & 2 & 10.0 \\
\hline & $41-55$ & 3 & 15.0 \\
\hline & $56-70$ & 9 & 45.0 \\
\hline & $71-80$ & 6 & 30.0 \\
\hline & Total & $\mathbf{2 0}$ & $\mathbf{1 0 0 . 0}$ \\
\hline Jenis Kelamin & Laki-laki & 10 & 50.0 \\
\hline & Perempuan & 10 & 50.0 \\
\hline & Total & $\mathbf{2 0}$ & $\mathbf{1 0 0 . 0}$
\end{tabular}

Tabel 1. Distribusi Frekuensi dan Persentase Responden Menurut Tingkat

\begin{tabular}{llcc}
\hline & & Frekuensi & Persentase $(\%)$ \\
\hline Jenis Stroke & Stroke Hemoragic & 14 & 70.0 \\
\hline & $\begin{array}{l}\text { Stroke Non } \\
\text { Hemoragic }\end{array}$ & 6 & 30.0 \\
\hline & Total & $\mathbf{2 0}$ & $\mathbf{1 0 0 . 0}$
\end{tabular}

Tabel 3. Distrbusi Frekuensi dan Persentase Jenis Stroke Responden di RSUD Haji Makassar dan RSUD Kota Makassar n=20

\begin{tabular}{cccc}
\hline & & Frekuensi & Persentase $(\%)$ \\
\hline Derajat Disphagia & Derajat 1 & 14 & 70.0 \\
\hline & Derajat 2 & 6 & 30.0 \\
\hline Derajat 3 & 0 & 0.0 \\
\hline Total & $\mathbf{2 0}$ & $\mathbf{1 0 0 . 0}$ \\
\hline
\end{tabular}

Tabel 4. Distribusi Responden Berdasarkan Derajat Disfagia di RSUD Haji Makassar dan RSUD Kota Makassar n=20

\begin{tabular}{clcc}
\hline & Frekuensi & Persentase $(\%)$ \\
\hline $\begin{array}{c}\text { Kemampuan } \\
\text { Menelan }\end{array}$ & Normal & 0 & 0.0 \\
\hline & Tidak Normal & 20 & 100.0 \\
\hline & Total & 20 & 100.0 \\
\hline & Total & $\mathbf{2 0}$ & $\mathbf{1 0 0 . 0}$ \\
\hline
\end{tabular}

Tabel 5. Distribusi Frekuensi dan Persentase Kemampuan Menelan Sebelum dilakukan Latihan Menelan pada Pasien Stroke dengan Disfagia di RSUD Haji Makassar dan RSUD Kota Makassar n=20 


\begin{tabular}{clcc}
\hline & Frekuensi & Persentase $(\%)$ \\
\hline $\begin{array}{c}\text { Kemampuan } \\
\text { Menelan }\end{array}$ & Normal & 14 & 70.0 \\
\hline & Tidak Normal & 6 & 30.0 \\
\hline & Total & 20 & 100.0 \\
\hline & Total & $\mathbf{2 0}$ & $\mathbf{1 0 0 . 0}$ \\
\hline
\end{tabular}

Tabel 6. Distribusi Frekuensi dan Persentase Kemampuan Menelan Setelah dilakukan Latihan Menelan pada Pasien Stroke dengan Disfagia di RSUD Haji Makassar dan RSUD Kota Makassar $n=20$

2. Analisis Bivariat

\begin{tabular}{cccc}
\hline Variabel & Shapiro-Wilk & Sig \\
\hline $\begin{array}{c}\text { Sebelum Latihan } \\
\text { Menelan }\end{array}$ & Statistic & Df & 0.097 \\
\hline $\begin{array}{c}\text { Setelah Latihan } \\
\text { Menelan }\end{array}$ & 0.920 & 20 & 0.752 \\
\hline & Total & 20 & $\mathbf{1 0 0 . 0}$ \\
\hline
\end{tabular}

Tabe1 7. Uji Normalitas

\begin{tabular}{|c|c|c|c|c|}
\hline & Rerata (s.b) & Selisih (s.b) & IK 95\% & Nilai p \\
\hline $\begin{array}{c}\text { Sebelum Latihan } \\
\text { Menelan }\end{array}$ & $60.60(3.9)$ & $20.10(4.66)$ & $17.9-22.26$ & $<0.001$ \\
\hline $\begin{array}{c}\text { Setelah Latihan } \\
\text { Menelan }\end{array}$ & $80.70(4.2)$ & & & \\
\hline
\end{tabular}

Tabel 8. Pengaruh Latihan Menelan pada Pasien Stroke dengan Disfagia di RSUD Haji Kota Makassar $n=20$

Berdasarkan tabel 7 diatas menunjukkan bahwa setelah menggunakan uji normalitas Shapiro Wilk didapatkan nilai $p=0,752$ dan nilai sig $>0,05$, sehingga data berdistribusi normal. Dari hasil uji statistic dengan Paired Sampel T-Test (Tabel 8) menunjukkan bahwa dengan nilai $\mathrm{p}<0,001(\mathrm{p}<0,05)$, maka dengan demikian Ha diterima yang artinya ada pengaruh latihan menelan pada pasien stroke dengan disfagia di RSUD Haji Makassar dan RSUD Kota Makassar.

\section{PEMBAHASAN}

Berdasarkan hasil penelitian yang diperoleh, kemudian dianalisis menggunakan uji normalitas untuk mengetahui sebaran data berdistribusi normal atau tidak. Dalam hal ini menggunakan uji Shapiro wilk dan dapatkan hasil $p=0,820$ ( $p>0,05)$, yang artinya sebaran data berdistribusi normal dan diperkuat juga dengan menggunakan uji deskriptif hitung berdasarkan koefisien varian, rasio skewness, dan rasio kurtosis dan hasil data juga berdistribusi normal. Setelah mengetahui sebaran data normal, dilanjutkan dengan menganalisis hasil statistik dengan menggunakan uji $\mathrm{T}$ berpasangan (Paired Sampel T-Test) didapatkan nilai $\mathrm{p}<0,001,(<0,05)$. Dengan demikian hasil penelitian ini diperoleh bahwa ada pengaruh antara latihan menelan pada pasien stroke dengan disfagia yang berarti Ho ditolak.

Hasil penelitian ini menunjukkan bahwa setelah diberikan perlakuan latihan menelan pada 20 responden stroke dengan disfagia dimana latihan menelan dilakukan minimal 3 kali dalam sehari dalam satu minggu yang status menelannya di observasi pada hari pertama sebelum diberikan perlakuan dan dihari ketujuh setelah perlakuan latihan menelan. Semua perlakuan yang diberikan terhadap 
responden juga sama yaitu hanya satu minggu perlakuan tanpa membedakan derajat disfagia. Dari hasil tersebut didapatkam dari total 20 responden yang sebelumnya tidak dapat menelan secara normal terdapat 14 responden menjadi normal status menelannya (70\%) dan 6 responden masih tidak normal status menelannya (30\%). Adapun perubahan yang terjadi pada responden stroke hemoragik ini karena pertama kalinya responden mengalami serangan stroke dan telah dirawat selama 10 hari diruang perawatan dan ada juga yang telah masuk ditahap pemulihan pasca dirawat di ruang ICU selama 21 hari. Maka dari itu responden mengalami perubahan status fungsi menelan karena responden kooperatif dalam melakukakn latihan menelan.

Hari pertama penelitian sebelum melakukan perlakukan responden di observasi terlebih dahulu setelah itu baru diberikan latihan menelan. Pada kebanyakan responden baik itu stroke hemoragik dan non stroke hemoragik belum terlihat adanya perubahan, hal ini dikarenakan pasien malas untuk makan hal ini karena responden merasa mual, hanya ingin tidur saja, dan tidak bisa melakukan instruksi yang diberikan oleh peneliti yaitu latihan otot-otot menelan misalnya membuka mulut berbentuk "O", tidak dapat sepenuhnya mengeluarkan lidah, membuat lidah menyentuh bibir atas bawah, samping kanan kiri, bicara tidak jelas, bibir nampak tidak simetris, tidak mampu mengemut permen lolipop, ROM pada lidah masih terbatas, kurang mampu mengunyah makanan hingga membentuk bolus, sangat lambat memindahkan makanan dari mulut ke faring, hanya mampu menelan makanan sebanyak 1-2 sendok makan dengan toleransi makanan kental tanpa sayur dan lauk, dan nampak responden terlihat ingin muntah dan peneliti membantu menggerakkan kepala responden ke posisi yang lemah, masih tidak mengerti dan tidak mampu untuk melakukan teknik mandelson manuver pada saat menelan.

Hari kedua, pada 2 responden non hemoragik stroke dan 6-7 pasien non hemoragik stroke terlihat begitu kooperatif dalam melakukan latihan menelan walaupun belum mampu melakukan latihan menelan itu sendiri. Kemudian pada kebanyakan responden terlihat masih tidak mampu melakukan latihan otot menelan. Suara nafas masih terdengar serak, hanya bisa mengikuti satu perintah saja, gerakan lidah masih sangat terbatas, sangat lambat menelan makanan $>5$ detik dan toleransi makanan masih kental tanpa sayur dan lauk sebanyak 1-2 sendok makan, masih sangat lambat untuk mengosongkan mulut dan masih dibantu untuk menolehkan kepala ke posisi yang lemah dan belum bisa untuk memegang jakun pada saat menelan. Pada hari ketiga responden stroke hemoragik dan non hemoragik stroke kurang bisa melakukan gerakan latihan otot-otot menelan misalnya mampu mengeluarkan lidah tapi masih terlihat lidah bergetar dan tidak bisa terlalu lama menahan lidah maupun mulut hingga delapan hitungan hanya bisa $2-3$ hitungan saja. Pada saat makan juga responden masih terlihat terbatas dalam mengunyah makanan sehingga tidak dapat membentuk bolus dan masih sangat lambat menelan makanan, hanya makan 2-3 sendok makan saja dan sudah sedikit bisa untuk menolehkan kepala ke posisi yang lemah serta memegang jakun pada saat menelan namun hanya beberapa saat.

Pada hari keempat 12 responden non hemoragik stroke dan 4 stroke hemoragik sudah dapat melakukan latihan otot menelan dengan mampu membuka mulut, mengemut permen walaupun hanya sejenak, mengeluarkan dan menyentuh lidah walaupun hanya dalam 4 hitungan saja, lidah masih mengalami gangguan ringan, bibir tampak masih kurang simetris, refleks batuk lemah, kurang mampu membentuk bolus, masih lambat dalam memindahkan 
makanan dan toleransi makanan hanya menggunakan bubur dan air sayur sebanyak 2-4 sendok makan dan juga responden sudah bisa untuk menolehkan kepala ke posisi yang lemah dan memegang jakun pada saat menelan. Pada hari kelima 4 responden stroke hemoragik dan 12 non hemoragik stroke mulai bisa melakukan latihan otot-otot menelan dengan baik maupun hanya mampu menahan 4-6 hitungan, mampu mengemut permen yang diberikan, Hal ini dapat memudahkan responden untuk mengunyah makanan, dan memindahkan makanan dari mulut ke pharink.

Pada hari keenam kebanyakan responden non stroke hemoragik dan 2 stroke hemoragik mampu melakukan latihan menelan dengan baik dan terstruktur. Kebanyakan bibir pasien masih terlihat sedikit tidak simetris, bicara masih kurang jelas, gangguan ROM ringan pada daerah lidah serta bagian tangan namun batuk volunter lemah. Pada saat mengunyah respoden masih menyisakan makanan didalam mulut, lambat memindahkan makanan 1-5 detik, dan agak lambat untuk menelan makanan 1-2 detik dengan toleransi makanan lunak dan cair dengan lauk yang diberikan dan juga responden sudah mandiri untuk menolehkan kepala ke posisi yang lemah dan memegang jakun pada saat menelan sampai hitungan 5-7 .

Hari terakhir setelah diberikan perlakuan, 12 pasien non stroke hemoragik mampu secara mandiri melakukan tekhnik latihan otototot menelan walaupun pada pasien stroke hemoragik dan 2 pasien non hemoragik masih butuh bantuan dalam melakukan latihan menelan seperti mengeluarkan lidah, menyentuh bibir atas, bawah samping kanan dan kiri sampai delapan hitungan. Dan juga kebanyakan responden mampu melakukan tehnik latihan menelan secara langsung dan tidak langsung tanpa diingatkan dan dibantu lagi. Suara nafas terdengar bersih, bicara terdengar sedikit jelas, lidah mampu membuat bolus pada makanan, sering batuk, tidak menyisakan makanan dimulut, terkadang lambat memindahkan dan menelan makanan dengan toleransi makanan lunak dan cair dsebanyak 8-10 sendok makan.

Pada 20 responden masih ada 6 responden yang mengalami ketidaknormalan dalam status menelan hal ini dikarenakan kurangnya motivasi pasien untuk melakukan latihan penguatan otototot menelan, latihan bibir, latihan lidah, menolehkan kepala keposisi yag lemah, dan melakukan mandelson manuver serta ketidakmampuan responden melakukan sendiri latihan menelan itu sendiri karena responden mengalami perdarahan dibagian otak dan hemiparese pada sebagian tubuh klien. sedangkan latihan ini bertujuan untuk meningkatkan kekuatan otot mengunyah, menelan makanan, dan merubah fisiologi menelan responden secara langsung maupun tidak langsung.

Penelitian ini sejalan dengan penelitian McCullough dan Kim (2013), diperoleh 18 pasien stroke dengan disfagia setelah diberi perlakuan latihan menelan dalam hal ini teknik mandelson manuver didapatkan peningkatan kemampuan menelan setelah satu minggu latihan menelan.

Hasil penelitian ini berkolerasi dengan penelitian yang dilakukan oleh Ismansyah (2008) yang mengatakan bahwa pengaruh latihan menelan terstuktur pada pasien stroke dengan disfagia signifikan terhadap peningkatan kemampuan mengunyah dan menelan pada pasien stroke dengan disfagia.

Hasil penelitian Squires (2006) mengatakan bahwa latihan lidah baik aktif maupun pasif bertujuan untuk meningkatkan kemampuan manipulasi bolus dan kemampuan mendorong bolus dari rongga mulut masuk ke esophagus melalui faring. Sedangkan latihan gerak rahang berguna untuk pergerakan rahang dalam proses 
mengunyah.

Hal ini sejalan dengan teori yang mengatakan bahwa salah satu terapi menelan pada stroke dengan disfagia adalah Indirect Swallow Therapy yaitu mengajarkan pasien untuk menjalani latihan memperkuat otot yang lemah untuk mengatasi kesulitan menelan (Rasyid, 2015).

Penelitian ini sejalan dengan teori yang mengatakan bahwa latihan menelan secara teratur tiga kali sehari juga bertujuan untuk memberikan stimulasi pada reseptor refleks menelan yang terdapat pada arkus faring. Stimulasi pada arkus faring ini dapat dilakukan pada saat intervensi oral hygienen atau pada waktu memberikan makan dengan modifikasi diet. Diharapkan dengan dilatih secara teratur tiga kali sehari mampu mengembalikan fungsi menelan pasien kembali pulih secara optimal dan dapat mencegah terjadinya aspirasi (Rasyid \& Soertidewi, 2011)

Hal ini sejalan dengan teori yang mengatakan bahwa latihan menelan atau swallowing therapy merupakan suatu intervensi keperawatan yang mencakup metode langsung dan tidak langsung. Metode tidak langsung atau menuver kompensatori bertujuan meningkatkan kekuatan otot-otot menelan tanpa merubah secara langsung fisiologi menelannya.. Sedangkan untuk latihan menelan menggunakan metode langsung dirancang untuk merubah fisiologi menelan dan membutuhkan partisipasi langsung dari pasien, yang termasuk dalam metode ini adalah The Mandelsohn Manuver (Mulyatsih \& Ahmad, 2015).

Berdasarkan hasil penelitian, teori pendukung dan penelitian sebelumnya, maka peneliti berkesimpulan bahwa peningkatan kekuatan otot-otot latihan menelan sangat penting dilakukan agar membuat makanan mudah untuk menjadi bolus sehingga lebih aman untuk pasien melakukan proses menelan. Terjadi perubahan fisiologi menelan pada pasien stroke adalah dengan dilakukannya tekhnik langsung yaitu Mandelshon Manuver yaitu bertujuan membuka sfingter osefagus untuk mencegah terjadinya aspirasi. Selain itu untuk mengimbangi kesulitan menelan perlu juga dilakukan tekhnik kompensatori atau tekhnik tidak langsung seperti melakukan pengaturan posisi kepala, menolehkan kepala ke posisi tubuh yang lemah serta mengemut permen lolipop untuk melatih otot - otot rahang responden. Dapat juga dilihat dari perbedaan status fungsi menelan pasien sebelum dan sesudah latihan menelan, hal ini sangat penting untuk dilakukan karena dapat memperbaiki status nutrisi dan meningkatkan kemampuan menelan pasien.

\section{KESIMPULAN}

Ada pengaruh latihan menelan pada pasien stroke dengan disfagia di RSUD Haji Makassar dengan melihat perbandingan status fungsi menelan pasien stroke sebelum latihan menelan dengan sesudah dilakukan latihan menelan dengan hasil $\mathrm{p}<0,001$.

Diharapkan kepada bagian kesehatan khususnya perawat bahwa apabila menemkan pasien stroke dengan disfagia agar kiranya lebih memperhatikan kemampuan menelan dan status nutrisi pasien dengan melakukan teknik latihan menelan terstruktur agar kebutuhan nutrisi pasien terpenuhi.

Diharapkan penelitian berikutnya melihat lebih lanjut tentang pengaruh latihan menelan pada pasien stroke dengan membedakan derajat disfagia dan lamanya perlakuan yang diberikan pada pasien stroke hemoragik untuk mengembangkan penelitian yang lebih mendalam untuk pelayanan kesehatan.

\section{DAFTAR PUSTAKA}

Jenny, J.C. Lidwina, S. and Angliadi, E. (2014). Rehabilitasi Medik pada Penderita Disfagia. Jurnal Biomedik (JBM). Vol. 6. No. 3. November 2014. Dipetik Oktober 12, 2016 dari ejournal.unsrat. ac.id/index.php/biomedik/article/ download/6321/5841 pukul 16.00 WITA 
Ismansyah. (2008). Pengaruh Latihan Mengunyah dan Menelan Terstruktur Terhadap Kemampuan Mengunyah dan Menelan Dalam Konteks Asuhan Keperawatan Pada Pasien Stroke dengan Disfagia di RSUD Abdul Wahab Sjahranie Samarinda. Skripsi diterbitkan. Depok : Fakultas Kedokteran - Universitas Indonesia. Diakses dari lib.ui.ac.id/ file?file=digital $/ 127168 .$. Pengaruh $\% 20$ latihan-HA.pdf

Kemenkes. (2016). Diakses dari www. antarasulsel.com/berita/55730/ prevalensi-ptm-di-makassar lampauiprevalensi-nasional. Pada tanggal 19 Oktober 2016 pukul 04.00 WITA

McCullough, G \& Kim, Y. (2013). Effect of the Mendelsohn Maneuver on Extent of Hyoid Movement and UES Opening Post-Stroke1. NIH Public Access. Vol. 28. No. 4. Dipetik November 8, 2016. DOI : doi:10.1007/ s00455-013-9461-1. pukul 19.00 WITA

Mulyatsih , Enny \& Ahmad, Airiza. (2015). Petunjuk Perawatan Pasien Pasca Stroke di Rumah. Jakarta: FKUI.

Rani, Parkodi, \& Seethalakshmi. (2013). Effectiveness of Dysphagia Exercises on
Swallowing Ability Among Patients with CVA. Journal of Science. Vol 3. Issue 2. 76. Dipetik October, 14, 2016. DOI: www. journalofscience.net. pukul 16.15 WITA.

Rasyid, Al \& Soertidewi, Lyna. (2011). Manajemen Stroke secara Komprehensif. Jakarta: FKUI.

Rasyid, Misbach, \& Harris. (2015). Komplikasi Medis \& Tata Laksana. Jakarta: FKUI.

Riskesdas. (2013). Diakses dari Riset kesehatan dasar. Diakses dari www.depkes.go.id/ resources/download/general/Hasil\%20 Riskesdas\%202013. Pada tanggal 12 Oktober 2016 pukul 16.45 WITA

Smithard, David G. (2014). Swallowing Rehabilitation After Stroke. Int J Phys Med Rehabil, 2(2), 2-8. Dipetik Oktober 12, 2016, dari http://dx.doi. org/10.4172/2329-9096.1000191 pukul 16.31 WITA

Squires, N. (2006). Dysphagia Management of Progressive Neurological Conditions, Neuroscience. Nursing Journal. (Vol. 20) http:// proquest.umi.com/pqdweb?index $=190 \&$ did $=1020191231$. Diakses tanggal 19 Januari 2017 